\title{
Presencia y actuación española en la 30 Reunión de Técnicos de la Industria del Cemento del Brasil
}

\author{
Río de Janeiro, octubre de 1979
}

Prof. Dr. Jose Calleja

Vicedirector del IETCC

Madrid (España)

\section{INTRODUCCION}

Con ocasión de su asistencia por parte española a la 2. ${ }^{a}$ Reunión del GLAICYC (Grupo Latino-Americano de Instituciones del Cemento y del Concreto) en Río de Janeiro, el que esto escribe fue una vez más (la cuarta) invitado a participar activamente en la 30. RTIC del Brasil, celebrada en el Club de la Aeronáutica de Río de Janeiro, y a continuación de la Reunión mencionada en primer término.

La invitación fue hecha desde Brasil por el Prof. Ing. Francisco de Assis BASILIO y por el Ing. Argos MENNA BARRETO, Presidente del Consejo Técnico y Secretario Ejecutivo, respectivamente, de la $\mathrm{ABCP}$ (Asociación Brasileña del Cemento Portland), muy pocos días antes de la partida del invitado para asistir a la 2. ${ }^{a}$ Reunión del GLAICYC.

El programa previsto para dicha $30 .^{a}$ Reunión organizada por la $\mathrm{ABCP}$ fue el siguiente:

Día 18 de Octubre de 1979

$09.00-10.00 \mathrm{~h}$ a) El VII Congreso Internacional de Química del Cemento.

b) Aspectos de la Normalización Internacional y Nacional (ABNT: Asociación Brasileña de Normas Técnicas).

Prof. Ing. Francisco de Assis BASILIO (ABCP).

10.00 - $11.00 \mathrm{~h}$ Desempeño cualitativo de los cementos brasileños.

Ing. Hans Roman Edmundo BUCHER (ABCP).

$11.00-11.30 \mathrm{~h}$ Intervalo. Café. 
11.30 - 12.30 h La contribución de la industria del cemento al control de la contaminación y a la racionalización del empleo de la energía.

Ing. Quím. Volney Nascimento RIBEIRO (Fábrica IRAJA, Río de Janeiro).

$12.30-14.30 \mathrm{~h}$ Cementos con adiciones.

Prof. Dr. José CALLEJA (IETCC, Madrid, España).

15.30 - 16.30 h Suministro de carbón mineral a la industria brasileña de cemento.

Ings. Alexandre PEREZ PRADO y Fabricio Adalberto DE ALMEIDA LEITE (CAEEB).

$16.30-17.00 \mathrm{~h}$ Intervalo. Café.

17.00 - $18.00 \mathrm{~h}$ Estructura del consumo de combustibles en la industria brasileña del cemento.

Ing. Argos MENNA BARRETO (ABCP).

Este programa inicial fue modificado en el sentido de que, a partir de las 10.00 horas y hasta las 12,30 , la mañana del día asignado a esta $300^{2}$ Reunión fue íntegramente dedicada, sin interrupción por el intervalo previsto, a la conferencia sobre "Cementos con Adiciones", de una hora de duración aproximada, seguida de un prolongado coloquio nutrido de preguntas y planteamientos de cuestiones. La razón del cambio fue la partida del conferenciante hacia España en la tarde del mencionado día.

\section{CEMENTOS CON ADICIONES*}

\section{Prof. Dr. José CALLEJA}

\section{Vicedirector del IETCC (MADRID-España)}

Presentado el conferenciante por el Prof. Ing. F. de A. BASILIO, éste le cedió la palabra. En lo que sigue se hace un desarrollo de lo que aquél expuso, no siempre teniendo en cuenta el orden real de la exposición, sobre todo en lo que al Coloquio se refiere; pero sí en general en cuanto concierne al contenido principal de los mismos. La forma explicativa en tercera persona obedece a la falta de texto escrito, incluso de guión con que esta conferencia fue desarrollada por el expositor, por los motivos que se indican en lo que sigue.

El conferenciante comenzó agradeciendo a la $\mathrm{ABCP}$ en las personas del Prof. BASILIO y del Ing. MENNA BARRETO la invitación —cuarta- que la Asociación le hacía para tomar parte activa en su 30. Reunión.

Se excusó de antemano por la improvisación que había de hacer en la exposición del tema, dada la falta de tiempo para una preparación más formal del mismo, en vista de la fecha recentísima en que se le había hecho la invitación con el encargo de hablar sobre Adiciones para Cementos y Cementos con Adiciones.

* Memoria de la Conferencia-Coloquio desarrollada po: el autor en la 30.a Reunión de Técnicos de la Industria del Cemento del Brasil. 
Indicó que, en consecuencia, haría una exposición general del tema y que, dada la amplitud del mismo, iría señalado a lo largo de ella los puntos cruciales que a su juicio y a manera de "provocación", podrían y deberían ser objeto de más amplio desarrollo y debate en el coloquio que habría de seguir. Solicitó asimismo que en dicho coloquio se le hiciesen las preguntas y observaciones y se le planteasen los problemas concretos que los asistentes juzgasen de su más directo interés en relación con el tema. Y sin más preámbulo pasó a desarrollar éste.

Comenzó haciendo una justificación de los cementos con adiciones como solución al problema de la insuficiencia — cuando no de la deficiencia-, en determinados usos y tipos de obra de los cementos portland (entendiendo por tales en lo sucesivo los "puros" constituidos exclusivamente por clínker y yeso u otro regulador del fraguado).

Citó a tales efectos las distintas propiedades y los diferentes comportamientos de los cementos en relación con sus características químicas - composición- y físicas - finura y granulometría-, en cuanto a su inflluencia en parámetros tales como el calor de hidratación, la velocidad de endurecimiento y de desarrollo de resistencias, la estabilidad - expansión, retracción y fisuración-, la durabilidad - resistencia frente a ataques de tipo químico-, etc., así como en el comportamiento reológico del hormigón fresco, en la segregación, en la sedimentación, en la exudación — rezumado o "bleeding"-, etc., y en la corrosión de las armaduras de los hormigones armados y pretensados.

Puso ejemplos de adecuación e inadecuación de distintas variedades de cemento portland según la finalidad de su utilización. Así, los cementos portland ricos en silcato tricálcico -alíticos-y en aluminato tricálcico - dijo--, son aptos para hormigones de grandes resistencias y para la prefabricación -incluso sin tratamientos higrotérmicos aceleradores-, por su mayor velocidad de endurecimiento y el más rápido desarrollo de sus resistencias: incluso a edades tempranas. Pero en cambio - añadió-, no son aptos para hormigones de presas, sobre todo con dosificaciones de cemento no muy bajas, por su gran calor de hidratación, el cual puede elevar demasiado la temperatura de grandes masas de hormigón, con el peligro de su fisuración por retracción, al experimentar fuertes choques térmicos entre el día y la noche, en determinados lugares y condiciones; pues sabida es - dijo-, la escasa conductividad térmica del hormigón y su comportamiento casi adiabático, sobre todo en bloques de gran espesor, con granides masas generadoras de calor y con poca superficie de transmisión y enfriamiento.

Otra razón de lo inadecuado de estos cementos para presas -añadió- es la menor durabilidad de los hormigones con mayores contenidos de cal de hidrólisis sujeta a lixivación, y más aún si ésta tiene lugar con percolación a través de fisuras y grietas de los paramentos, posiblemente producidas por la mencionada retracción térmica y/o hidráulica; pues también es sabido -apuntó-, que el silicato tricálcico proporcionalmente libera mayor cantidad de cal de hidrólisis que el silicato bicálcico, y que los contenidos altos de aluminato tricálcico, si no están debidamente compensados con la cantidad adecuada de yeso, pueden producir retracciones mayores.

Tampoco son aptos tales cementos - prosiguió- para cimentaciones, y obras en terrenos yesíferos, ni para estructuras marítimas tanto sumergidas como sometidas a las mareas -alternancias de inmersión y emersión-, por su elevado contenido de aluminato tricálcico, pues es bien patente la reactividad de este constituyente con los sulfatos para formar la ettringita expansiva con carácter disruptivo. Ettringita - dijo-, cuya formación se ve además favorecida por la abundante cal de hidrólisis — aspecto ya mencionado- de dichos cementos.

Por las razones contrarias - continuó- los cementos portland ricos en silicato bicálcico 
-belíticos-, y sobre todo si tienen moderado o bajo contenido de aluminato tricálcico, son más aptos para presas, cimentaciones en terrenos yesíferos y obras marítimas, y en cambio son inadecuados para estructuras que exijan grandes resistencias a corto plazo, o para la prefabricación de elementos de hormigón - sobre todo sin tratamientos higrotérmicos-.

Desde el punto de vista de los hormigones armados y pretensados — dijo el conferenciante-, los cementos alíticos confieren a las armaduras una mayor y, sobre todo, más larga protección que los belíticos; ya que al elevado $\mathrm{pH}$ de las pastas cementantes suman una mayor reserva alcalina - precisamente de cal de hidrólisis-, la cual mantiene de forma más fácil y duradera el estado electroquímico de pasividad del acero, incluso en circunstancias desfavorables de lixivación del hormigón.

A propósito de todo lo anterior el conferenciante hizo unas consideraciones "filosóficas", en el sentido de que ningún tipo de cemento tiene cualidades sólo positivas o sólo negativas en ningún sentido, sino que en cualquier cemento unas y otras se encuentran inseparablemente entremezcladas: resistencia mecánica y protección de armaduras frente a calor de hidratación, a estabilidad y a resistencia química. Lo cual —dijo — exige elegir, con el mejor criterio en cada caso, el cemento más idóneo para el mismo, para lo que son muy útiles las recomendaciones y códigos de buena práctica para el mejor empleo de los cementos.

Después de estas consideraciones basadas en las características químicas -composicióndel cemento, pasó a hacer otras similares fundamentadas sobre la finura, como característica física principal del mismo. A igualdad de todo lo demás - dijo-, un cemento presenta más retracción cuanto mayor es su finura de molido. Pero la finura expresada en términos de superficie específica -BLAINE: $\mathrm{cm}^{2} / \mathrm{g}$-, es decir, por un sólo valor numérico, dice poco acerca de lo que verdaderamente importa y es operante: la distribución granulométrica de las partículas de cemento por tamaños —o más comúnmente llamada "granulometría"-, la cual es representada por una curva (la curva granulométrica del cemento). No todos los tamaños de grano del cemento tienen la misma actividad y eficacia a todos o parte de los efectos - positivos o negativos - a considerar, sino que los demasiado finos son inoperantes por su hidratación completa excesivamente rápida, y los demasiado gruesos también, en parte, por su hidratación incompleta y lenta. Existe pues -dijo-, un tamaño óptimo (que se puede considerar comprendido entre las 10 ó 15 y las 30 ó 40 micras); pero, puesto que un cemento industrial no puede ser "monogranular", es preciso tender a que su curva granulométrica no sea muy extendida en cuanto a tamaños, sino que, por el contrario, sea "corta", sin demasiada cabeza ni cola; esto es, que el cemento no contenga ni excesivo número de partículas gruesas ni excesivo número de partículas finas.

A este respecto - añadió- se conoce una ley matemática propuesta por ROSIN, RAMMLER y SPERLING para expresar la distribución de partículas por tamaños y que se expresa por:

$$
P=100\left(1-e^{-b x^{\mathrm{n}}}\right)
$$

o bien

$$
R=100 e^{-b x^{n}}
$$

y

$$
\log \left(\log \frac{100}{R}\right)=n \cdot \log x+C
$$


expresión en la que $P$ y $R$ representan, en tantos por ciento, las cantidades de cemento que, respectivamente, pasan a través de cada tamiz de luz de malla $x$, o son retenidas por el mismo, siendo $b$ y $n$ constantes para cada material. A ella corresponde la representación lineal (doble logarítmica en ordenadas y logarítmica en abscisas) de BENNET.

Según lo precedente - dijo el conferenciante-, las rectas representativas de la composición granulométrica del cemento deben tener una determinada posición y tender a una ciertaa pendiente -máxima u óptima-, to cual equivale a limitar para cada material tanto el tamaño máximo como el mínimo; es decir, equivale a situar al cemento en la condición de granulometría más favorable y adecuada, dado que cuanto más pendiente es la recta tanto más tiende el cemento a la monogranularidad; y cuanto más rasa es, tanto mayor número de tamaños de partículas mayores tiene el cemento. Estas consideraciones -añadió-, habrán de ser de gran valor al tratar después de las adiciones y de los cementos que las contienen.

Pasó luego a tratar de éstas y dijo que, por de pronto, todas ellas ejercían, al menos al principio, es decir, principalmente a las primeras edades del hormigón, un efecto diluyente del cemento y, por lo tanto, atenuante, tanto de sus características positivas (velocidad de endurecimiento y desarrollo de resistencias mecánicas, y protección de armaduras), como negativas - según el aspecto que se considerase- (calor de hidratación, expansión y tal vez también retracción y susceptibilidad a los ataques químicos). En cambio, a edades más largas las diferencias —añadió-, en cuanto se refiere a resistencias mecánicas se achica, llegando a desaparecer, e incluso consiguiéndose en algunos casos resistencias mayores que con cementos sin adiciones. El efecto diluyente -aclaró- se manifiesta más en las resistencias mecánicas y en el calor de hidratación a los plazos más cortos, así como en las acciones físicas y químicas externas sobre los aluminatos hidratados y sobre la cal de hidrólisis - portlandita - a plazos más largos, acciones que suelen tener —dijo- efectos expansivos y/o debilitantes para el hormigón.

Las adiciones - continuó- según su naturaleza`se pueden comportar —en el límite- como absolutamente inertes, o manifestar una cierta actividad de un determinado carácter. A las totalmente o casi totalmente inertes les corresponde un papel casi exclusivo de "fillers" diluyentes del cemento, tal como queda expuesto, y así es en su mayor parte en el caso de la caliza —dijo-. En este caso puede hæaber otro efecto físico benéfico para el hormigón cuando el árido fino de éste - la arena - carece de los elementos más finos o escasea en ellos, pues entonces las adiciones del cemento los suplen y contribuyen a que se obtengan hormigones con una granulometría mejor y más completa, más plásticos en fresco y más compactos y menos porosos una vez fraguados y endurecidos.

Pero en el caso de las adiciones llamadas activas, además de las mencionadas acciones y efectos de tipo físico, hay otras de tipo químico que se manifiestan en dos formas diferenciadas y complementarias: la puzolanicidad y la hidraulicidad latente o potencial. La pri mera - continuó-, es específica de los materiales naturales o artificiales llamados puzolánicos (puzolanas naturales, cenizas volantes y arcillas térmicamente activadas) y consiste en la reacción de los elementos ácidos (principalmente sílice) de dichos materiales con la cal de hidrólisis del cemento, para dar silicatos hidratados hidráulicos análogos a los del clínker, a plazos algo más largos, los cuales, por su relación cal/sílice algo más baja y por su textura dan una pasta hidratada más cerrada e impenetrable. De aqui -aclaró-, que las resistencias mecánicas de los cementos puzolánicos, menores a edades cortas que las de los portland del mismo clínker molidos a igual finura, puedan ser iguales a las de éstos a edades largas, y mayores a edades más largas, sobre todo si la finura de molido del cemento puzolánico es mayor que la del portland, como de ordinario suele ocurrir. Y de aquí también — concluyó-, que los cementos puzolánicos sean los más idóneos 
para hormigones de presas, por su menor calor de hidratación, retracción térmica y fisuración, por su mayor impermeabilidad y por su menor susceptibilidad a la lixiviación de la cal de hidrólisis.

En cuanto a la hidraulicidad potencial o latente —prosiguió-, es específica de las escorias siderúrgicas, las cuales $-\mathrm{y}$ a diferencia de las puzolanas-, amasadas con agua fraguan y endurecen por sí solas en una cierta medida, si bien la cal de hidrólisis del cemento y el yeso que contiene el mismo actúan como activadores o catalizadores de dicha hidraulicidad. Hasta el punto -aclaró-, de que en los cementos europeos llamados supersulfatados (o sulfosiderúrgicos, o de yeso y escorias) las escorias forrman parte de los mismos en proporción de un 80-85 \%, con un 10-15\% de yeso y alrededor de un $5 \%$ de clínker. Justificó el empleo de los cementos con escorias (siderúrgicos y de horno alto) en los hormigones de obras marítimas, por su mayor resistencia al ataque por las sales, y en particular por el sulfato magnésico del agua de mar.

En definitiva — dijo acto seguido-, por lo expuesto se comprende que las adiciones pueden eliminar o atenuar bastantes de las insuficiencias o de las deficiencias de los cementos portland ordinarios en determinados usos y empleos de los mismos.

Pasó después a justificar el empleo de las adiciones en razón al ahorra de fuel-oil en la fabricación del cemento, con un razonamiento numérico simple: si el consumo energético térmico en la fabricación es de $950 \mathrm{kcal} / \mathrm{kg}$ de clínker producido y la potencia calorífica del fuel-oil es de $9.500 \mathrm{kcal} / \mathrm{kg}$ de fuel quemado, el consumo de fuel-oil por tonelada de clínker es de $100 \mathrm{~kg}$. Por lo tanto —dijo-, las sustituciones de clínker por adiciones entre 20 y 80 por ciento pueden suponer ahorros de fuel-oil comprendidos entre las mismas cuantías, por tonelada de cemento. También justificó, en algunos casos, el ahorro de $\mathrm{kWh}$ de energía eléctrica en molienda de cemento. En conclusión —dijo-, ésta del ahorro de combustible derivado del petróleo y de energía en general es en nuestros días y en las presentes circunstancias otra buena razón para recomendar y fomentar el uso de las adiciones y la fabricación de cementos que las contengan, como ya había dejado expuesto —dijo-, en su aportación a la $2 .{ }^{a}$ Reunión del Grupo de Instituciones Latinoamericanas del Cemento y del Concreto (GLAICYC) en días anteriores ("Consideraciones sobre la Economía de Combustibles y otros Derivados del Petróleo en la Fabricación y en la Utilización de los Cementos").

Pero no quiso concluir sin llamar la atención sobre los problemas y las dificultades que podrían surgir por la utilización indiscriminada de adiciones inadecuadas. Y dijo al respecto que no todas las fábricas, por su situación y por la de las fuentes de las adiciones -yacimientos, centrales termoeléctricas o plantas siderúrgicas- estaban en condiciones económicas de utilizarlas, atendiendo a los gastos de transporte; que algunas fábricas que se hallasen en tales condiciones podrían tal vez intentar utilizar como materiales "puzolánicos" algunos disponibles en sus cercanías, con escasas o nulas propiedades puzolánicas; y que eso podría crear problemas muy serios.

Entre ellos —dijo—, el de que cementos que contienen tales adiciones pueden dar lugar a hormigones con retracciones plásticas excepcionalmente grandes, sobre todo en elementos de gran superficie y poco espesor expuestos a la intemperie durante su fraguado, en condiciones de clima o tiempo caluroso y seco y con fuerte viento reinante. En tales condiciones - añadió-, se pueden producir fisuraciones y agrietamientos muy fuertes por evaporación rápida y desecación intensa del hormigón, a veces favorecida a su vez por una demanda excesiva de agua por parte de los cementos. Exceso de agua requerido para el amasado y puesta en obra de un hormigón con un comportamiento reológico anormal, pero que luego sobra y produce segregación de partículas finas, exudación y sedimentación, además de la fuerte retracción plástica al evaporarse.

56 
El motivo de todo ello suele estar a veces —explicó-, en una granulometría anormal de los cementos con adiciones, al utilizar como tales materiales inadecuados. En efecto - detalló-, volviendo a la representación doble logarítmica (ordenadas) y logarítmica (abscisas) de la granulometría de los cementos según BENNET, utilizando la ley de distribución exponencial expresada por ROSIN, RAMMLER y SPERLING queda claro que las adiciones de tipo puzolánico deben estar molidas a mayor finura que el clínker, a fin de que con su mayor superficie específica puedan fijar rápidamente y de manera lo más completa posible la cal de hidrólisis del clínker; es decir, a fin de que puedan ejercer su acción puzolánica del módo más perfecto y eficaz. Esto quiere decir — prosiguió-. que consideradas por separado las rectas representativas de las granulometrías del clínker y del material puzolánico, las del segundo deben situarse por encima de las del primero -y a ser posible tener una mayor pendiente- y no a la inversa. Esto - dijo-, es lo que acontece de ordinario, pues los materiales puzolánicos suelen ser más blandos que el clínker, tanto los naturales como las arcillas termoactivadas - y no se diga las cenizas volantes, que ya por su origen y formación tienen una superficie específica muy elevada-

(A propósito de las cenizas volantes dijo que, según se utilizaran directamente en el hormigón, es decir, añadidas en la hormigonera o incorporadas al cemento por molienda conjunta con el clínker, los efectos podrían ser distintos, a igualdad de todo lo demás, en cuando el comportamiento reológico del hormigón. En efecto -aclaró-, las cenizas volantes contienen una cierta proporción de "cenosferas", especie de esférulas huecas de un material vítreo fundido, las cuales se destruyen, al menos parcialmente, durante la molienda del cemento; pero que quedan como tales y sin romper cuando se añaden directamente a la mezcla en la hormigonera. En este segundo caso -explicó-, las cenosferas se comportan en el hormigón fresco como las burbujas de aire del hormigón al que se añaden inclusores de aire, modificando la reología de éste, así como su plasticidad, escurrimiento, etc.).

Pero —añadió-, cuando no sucede así, (es decir, cuando se utilizan como pretendidas puzolanas materiales más duros, por ejemplo, de naturaleza ofítica o basáltica), las rectas representativas de sus granulometrías se sitúan por debajo de las rectas correspondientes al clínker $-\mathrm{y}$ tal vez con menor pendiente-, y esto da lugar a materiales pulverulentos más "agrios", los cuales dan pastas de menor plasticidad, para las que exigen mayor cantidad inicial de agua, que después sobra, con todos los inconvenientes ya señalados.

El expositor repitió a este respecto la observación (y la recomendación) —ya hechas días antes en la reunión del GLAICYC-, acerca de un mayor y mejor entendimiento entre técnicos de la fabricación y de la utilización del cemento (cementeros y hormigoneros), a base de un mejor y mayor conocimiento de las técnicas de los unos por parte de los otros, para evitar el planteamiento de problemas semejantes al expuesto. Quiso terminar con ello su exposición ("provocación") para dar paso al Coloquio general.

Se plantearon en éste, por parte de buen número de los técnicos brasileños asistentes a la conferencia, muchas cuestiones y muy diversas, entre las que cabe mencionar las siguientes: la evaluación de las adiciones puzolánicas en los cementos puzolánicos y en los cementos con adiciones activas; las características óptimas de las arcillas para su activación térmica puzolánica y los tratamientos más adecuados para ello; las adiciones de caliza al clínker en proporciones pequeñas y elevadas, según las actuales normas francesas para cementos; la molienda conjunta o por separado del clínker y de las adiciones; las características de las esccorias siderúrgicas para los cementos de horno alto; las posibilidades de utilización de otras escorias; los inconvenientes de algunos componentes minoritarios de las escorias; la regularidad de características resistentes de los cementos; etc. 
En cuanto a la evaluación de las adiciones puzolánicas —dijo el conferenciante-, se conocen y practican diversos ensayos para llevarla a cabo, y uno de los más conocidos y practicados es el basado en la propia definición de puzolana: su capacidad de reacción con la cal en presencia de agua, a la temperatura ordinaria, y de fijar dicha cal en forma de compuestos hidráulicos hidratados; y que algunas normas, entre ellas las de la ASTM, recomiendan y describen dicho método, no midiendo la cal fijada, sino las resistencias desarrolladas en probetas; pero que, a su juicio -el del expositor-, éste no es el método más adecuado, por cuanto que hoy día en la práctica ya no se utilizan las puzolanas mezcladas con cal, para tener morteros y hormigones como en tiempos de los romanos y posteriores, sino mezcladas con clínker; y que, en definitiva, lo que se debe ensayar y evaluar, tanto si se determina cal fijada como resistencias mecánicas, es el cemento puzolánico, que es lo que se emplea en las obras ya que, además, una puzolana determinada puede comportarse de forma distinta según el clínker con el que se mezcle y, recíprocamente, un clínker dado puede dar lugar a cementos de comportamiento diferente según la puzolana con la que se muela; pudiendo influir decisivamente en ambos casos la finura de molido del conjunto.

Añadió que, sobre esa base, uno de los métodos más idóneos y que respondía aceptablemente a la definición y al fundamento químico de la acción puzolánica era el de FRATINI, consistente en determinar, al cabo de un cierto tiempo, la situación representativa de un cemento adecuadamente tratado según el método experimental, con respecto a la curva isoterma de solubilidad (saturación) de la cal $\mathrm{CaO}(\mathrm{mM} / \mathrm{l})$ en presencia de alcalinidad $\mathrm{OH}^{-}(\mathrm{mM} / \mathrm{l})$ a $40^{\circ} \mathrm{C}$. Situaciones sobre la curva o por encima de la curva indican, respectivamente, saturación o sobresaturación de cal en la disolución y, por tanto, ausencia de fijación de cal, es decir, de acción puzolánica; en tanto que situaciones por debajo de la curva representan concentraciones de cal en la disolución inferiores a la de su saturación, causadas por fijación de cal en la fase sólida, y, en consecuencia, por acción puzolánica manifiesta.

En cuanto al aspecto cuantitativo del resultado del ensayo, es decir, respecto de la mayor o menor puzolanicidad del cemento según la situación de su punto representativo por debajo de la curva, dijo que las apreciaciones eran totalmente empíricas, y que el criterio de los especialistas italianos al respecto (Profs. Arturo RIO y Franco MASSAZZA, entre otros) era el de que un cemento puzolánico lo era sin reservas y a todos los efectos cuando la distancia de su punto representativo a la curva, medida sobre la línea paralela por el punto al eje de ordenadas, era del orden del 25 al 30 por ciento, o mayor, que la distancia de la curva al eje de abscisas, medida sobre la misma línea.

Con respecto a las edades o plazos a los que el ensayo de FRATINI se debía cumplir para poder considerar puzolánico a un cemento, el expositor dijo que eran variables según las normas de los distintos países; que los países con mejores puzolanas naturales propugnaban plazos más cortos (7-8 días), mientras que los que no las poseían tan buenas proponían plazos más largos (14-15 y hasta 28 días), y que incluso se habían formulado soluciones eclécticas en el sentido de que los cementos puzolánicos fuesen encuadrados en una u otra ide dos calidades, según cumpliesen a plazo más corto o más largo el ensayo de FRATINI. Habló también, a este respecto, de la situación del tema en el CEN (Comité Europeo de Normalización, de los países miembros -y allegados- al Mercado Común Europeo). E indicó - finalmente- que todo ello dependía, además, de la finura — superficie específica- de los cementos puzolánicos, a la que no siempre se fijaba un límite superior, y que en general era bastante superior a la, de los cementos portland ordinarios, con riesgo -a veces- de una mayor retracción.

En lo que atañe a los cementos con adiciones activas de naturaleza puzolánica -a los que los italianos llaman "cementos a la puzolana"-, el conferenciante dijo que, a dife- 
rencia de los genuinamente puzolánicos, cuyos contenidos de puzolana son altos (del orden del 25 ó 30 al 40 por ciento), aquéllos tenían contenidos menores, y que, en general, no se les exigía - ni había por qué- el cumplimiento del ensayo de FRATINI, el cual —añadió-, para un clínker y una puzolana dados, requiere, además de una determinada finura mínima, un contenido de puzolana tambiér mínimo. Se presenta el problema -aclaróde saber si un material presuntamente puzolánico es apto como tal para fabricar un cemento "a la puzolana". A su juicio - prosiguió-, este problema tiene una solución fácil, ya que se plantea para cada fábrica o línea de producción de cemento que utiliza su propio clínker y su propio material puzolánico. En tales condiciones bastaría fabricar con dichos materales un verdadero cemento puzolánico, con una proporción media de material puzolánico - por ejemplo, del 35 por ciento-, molido a una finura BLAINE también media, - por ejemplo, 4.000 ó $4.500 \mathrm{~cm}^{2} / \mathrm{g}$-, y ver si cumple con el ensayo de FRATINI al plazo fijado en la norma del país - si ese es el caso- para cementos puzolánicos. Si el resultado es positivo, el material supuestamente puzolánico lo será realmente, y será apto para fabricar cementos "a la puzolana". Este es —dijo-, un caso en el que un determinado material puede manifestarse como puzolánico o no, dependiendo, no sólo de su propia naturaleza sino también de la del clínker con el que se mezcla, de la proporción en que se haga y de la finura prefijada para el cemento resultante, lo cual responde en todo a la realidad práctica que se pretende: no se fija el clínker y sí sólo la proporción de mezcla y la finura en valores muy razonables.

El conferenciante respondió después a la pregunta sobre las arcillas y su activación térmica. Con respecto a la naturaleza más idónea de los materiales arcillosos para su tratamiento opinó que, dado el fundamento de la activación: rotura de enlaces químicos y formación de gran superficie interna para crear una reactividad frente a la cal, a base de los componentes ácidos activados (sobre todo sílice, aunque también alúmina), las arcillas más adecuadas debían ser aquéllas en las que los minerales arcillosos tienen relaciones $\mathrm{Si} / \mathrm{Al}$ ó $\mathrm{SiO}_{2} / \mathrm{Al}_{2} \mathrm{O}_{3}$ (o bien $\mathrm{Si} / \mathrm{Fe}$ ó $\mathrm{SiO}_{2} / \mathrm{Fe}_{2} \mathrm{O}_{3}$ ) mayores, como sucede respectivamente en las montmorilloníticas y en las nontroníticas, en las que tales relaciones se aproximan más a 2, a diferencia de lo que ocurre en las beidellíticas y en las nacríticas, en las que las relaciones se aproximan más a 1.

Por otra parte —añadió-, las arcillas más propicias para dar lugar a materiales activados de mayor superficie interna son aquéllas que tienen en su estructura mayor cantidad de agua de constitución interlaminar o zeolítica - entre capas tetraédricas de silício $\mathrm{y} / \mathrm{u}$ octaédricas de aluminio y/o hierro-, que al ser eliminada en el tratamiento deja estructuras más huecas y esponjosas. En tal sentido -agregó-, de nuevo las arcillas en que predomina la montmorillonita y/o la nontronita parecen ser las más idóneas.

Por lo que respecta al tratamiento óptimo en sí —concluyó-, corresponde a unas condiciones determinadas de temperatura y tiempo. En cuanto a temperatura, la más adecuada parece estar comprendida, en general, entre 750 y $850^{\circ} \mathrm{C}$; y, en cuanto al tiempo de tratamiento, puede ser variable dependiendo del sistema utilizado para el mismo. El no alcanzar la temperatura adecuada puede dejar material sin activar o poco activado, y el pasarse de ella puede desactivar el activado previamente; otro tanto puede decirse del tratamiento en sí, cuyas condiciones óptimas deben ser determinadas experimentalmente para cada material.

En lo tocante a las adiciones de caliza - "fíller"- en una u otra proporción al clínker -puntualizó-, hay que distinguir entre proporciones altas y bajas. Las altas, del orden del $35 \%$ - como están previstas en ciertos cementos de las actuales normas francesas y. españolas-, dan lugar a cementos de menor velocidad de endurecimiento y de resistencias más bajas a todas las edades - situación III de los correspondientes esquemas-, particularmente a las más tempranas. Dichos cementos son utilizables para trabajos de al- 
bañilería y similares -añadió-, pero nunca para fines estructurales, y así se hace constar en las normas mencionadas, y en las correspondientes normas para el hormigón -al menos en las españolas-. Esto es así —aclaró-, por la menor resistencia de la pasta cementante (sobre todo a la tracción), dada su relación agua/cemento real mucho mayor que la nominal, pues a tales efectos hay que contar la cantidad no depreciable de agua que exige y retiene la caliza refinada, y que no es necesaria para la hidratación, pero que crea poros, discontinuidades y pérdidas de adherencia de todo tipo.

Por otra parte - prosiguió-, las adiciones en menor cuantía ejercen una acción dispersante del cemento que es beneficiosa - aparte de las acciones físicas correctoras de posibles granulometrías deficientes, ya mencionadas al tratar de las adiciones en general-, sin contar con otras posibles acciones químicas epitáxicas dignas de ser tenidas en cuenta. A todos estos efectos citó los cementos portland "comerciales" de las pasadas normas españolas, los cuales podían contener hasta 10 por ciento de caliza, y que se han venido utilizando y exportando con éxito y sin complicaciones.

En lo que respecta a la molienda conjunta o por separado del clínker y de las adiciones en los cementos que las contienen, el expositor se remitió una vez más a la representación doble logarítmica de BENNET para la composición granulométrica de los cementos según ROSIN-RAMMLER-SPERLING, y dijo que las condiciones óptimas de mayor finura de la adición y menor del clínker - recta superior y más pendiente de la primera, e inferior y más tendida del segundo-, se conseguía más fácilmente con una molienda por separado, en la que en ambos casos se podían obtener composiciones granulométricas más tendentes a la monogranularidad (con menos excesos de finos y gruesos), perfectamente acoplables y sin problemas de homogeneidad de las mezclas, dados los modernos sistemas para conseguirla. Por vía de ejemplo —dijo-, los especialistas en el tema aconsejan, en el caso de los cementos de horno alto, moler por separado el olínker a $4.000 \mathrm{~cm}^{2} / \mathrm{g}$ de superficie específica, y la escoria a $6.000 \mathrm{~cm}^{2} / \mathrm{g}$, para evitar. la posibilidad de que con escorias más dunas que el clínker se obtengan, en la molienda conjunta de ambos, cementos con granulometrías desfavorables en los que la escoria constituya el componente más grueso idel producto.

En la cuestión correspondiente a las características de todo tipo exigibles a las escorias para la fabricación de cementos de horno alto, el conferenciante glosó las tres principales que se contemplan en las normas españolas para cemento: la condición de siderúrgicas, la condición de granuladas, y la condición de cumplimiento con un índice químico que acredite su naturalleza básica. La condición de siderúrgicas —dijo—, responde al hecho de que tales escorias, por su composición química, en el diagrama triangular del sistema ternario cal-sílice-alúmina se sitúan en una zona próxima a la de las composiciones de los cementos portland y menos próxima a la de los aluminosos, por lo que dichas escorias contienen en parte belita, gehlenita y akermanita, a las que, también en parte, deben sus propiedades hidráulicas latentes. La condición de granuladas (templadas, bien en agua o bien al aire) —prosiguió-, se debe a la mayor actividad hidráulica de los constituyentes en fase vítrea, en relación con los mismos constituyentes cristalinos, para una misma composición química. Y la condición de básicas -añadió-, va ligada al resto de la composición química según lo señalado, a través de una serie de índices o módulos, de los cuales el conferenciante expuso y comentó varios de los más usualmente adoptados.

En cuanto a la posibilidad de utilizar otras escorias siderúrgicas no básicas, o no tan básicas, como las definidas por los índices mencionados, e incluso distintas de las siderúrgicas, el conferenciante dijo que ello debía depender de las cirscunstancias; que, en principio, nada parecía oponerse a que un material al que se le exigía una cierta capacidad hidráulica fuese de naturaleza más ácida —en un sentido análogo al de acidez y basic1- 
dad de las rocas silícicas naturales- que las tradicionalmente conocidas y utilizadas escorias siderúrgicas básicas, con tal de que dicha hidraulicidad fuese debidamente catalizada por la cal de hidrólisis del clínker y/o por el yeso contenido en el cemento. Er. cualquier caso -agregó-. sería preciso ensayar las posibilidades de dichos materiales (por ejemplo las escorias siderúrgicas ricas en manganeso), tanto en condiciones usuale; como distintas de éstas, y tanto en lo referente a fraguado y resistencias mecánicas, como a estabilidad y durabilidad de los cemeritos resultantes, a corto, medio y largo plazo, en función del clínker utilizado y de la finura del cemento fabricado. Asimismo - concluyó-, no hay que perder de vista la posibilidad de que escorias de otras metalurgias distintas de las del hierro. ricas en sílice. puedan comportarse como puzolanas. A tal efecto recordó que desde el punto de vista de la durabilidad - resistencia química frentc: a ataques salinos al hormigón por suelos y agua de mar-, los cementos ternarios a base de clínker de bajo contenido de aluminato tricálcico, puzolanas activas y escorias siderúrgicas básicas, ambas de bajo contenido en alúmina, eran los más idóneos. Pero insistió en que era preciso estudiar a fondo la incidencia de los componentes menores y/o no usuales de las escorias en el comportamiento del cemento a todos los efectos y a todos los plazos.

Por lo que respecta a algunos de estos componentes minoritarios perjudiciales de las escorias, en el Coloquio se habló de los conteridos de azufre de las mismas en forma de sulfuros. particularmente cálcico y ferroso, y de la influencia de éstos en la corrosión fisurante (intergranular) del acero de los alambres bajo la tensión del pretensado, a causa del efecto de fragilización por hidrógeno, lo que haría a los cementos siderúrgicos poco adecuados para hormigones pretensados.

En el punto tocante a la regularidad de calidad de los cementos, y en particular en lo que se refiere a la variabilidad de las resistencias. el conferenciante expuso el hecho paradójico de que -con arreglo, por ejemplo. a las normas españolas-, cementos con resistencias de 349 y $351 \mathrm{~kg} / \mathrm{cm}^{2}$, difiriendo en sólo $2 \mathrm{~kg} / \mathrm{cm}^{2}$, fuesen de distinta categoría resistente (250 el primero y 350 el segundo). mientras que cementos con resistencias de $351 \mathrm{~kg} / \mathrm{cm}^{2}$ y $449 \mathrm{~kg} / \mathrm{cm}^{2}$, difiriendo en $98 \mathrm{~kg} / \mathrm{cm}^{2}$, fuesen ambos de la misma categoría resistente (350). Esto - dijo-, es el inconveniente de fijar las categorías por mínimos de resistencias, en vez de fijarlas por mínimos y máximos - como sucede ya en Alemaniz $y$ en Francia-. o por el valor medio de un intervalo razonablemente acotado.

Soluciones de este tipo -añadió-, ayudarían a evitar que cementos portland puros y cementos portland con adiciones activas, aún perteneciendo a una misma categoría resistente (por ejemplo 350), pudiesen dar resistencias muy diferentes a todas las edades, y bastante más bajas las de los segundos que las de los primeros. Lo cual -agregó- para hormigones con la misma dosificación exige mayor tiempo de encofrado, con el consiguiente retraso de las obras cuando se utilizan los cementos con adiciones activas; o implica - tal vez- dosificaciones mayores. si se quiere desencofrar en los mismos plazos que cuando se emplean cementos portland puros: o dificulta el trabajo de las centrales hormigoneras, de dar un hormigón de calidad suficientemente uniforme. so pena de rectificar con mucho mayor frecuencia las dosificaciones y de multiplicar los ensayos.

Por todo ello, el conferenciante insistió. aún una vez más - y con ello concluyó el Coloquio- en la necesidad del mejor entendimiento entre los técnicos del cemento y los técnicos del hormigón. a base de un mayor conocimiento de sus respectivos problemas.

Al final de esta exposición el autor presentr sus excusas por la posible - casi seguraomisión de algún tema o detalle de interés tratado en el Coloquio y no reflejado aquí. lo cual puede ser explicable por la larga duración del mismo y el abundante número de preguntas hechas, no todas registradas o recordadas. Y al mismo tiempo agradece de nuevo la invitación de la $A B C P$. 


\section{ROSIN-RAMMLER-SPERLING}

\section{(BENNET)}

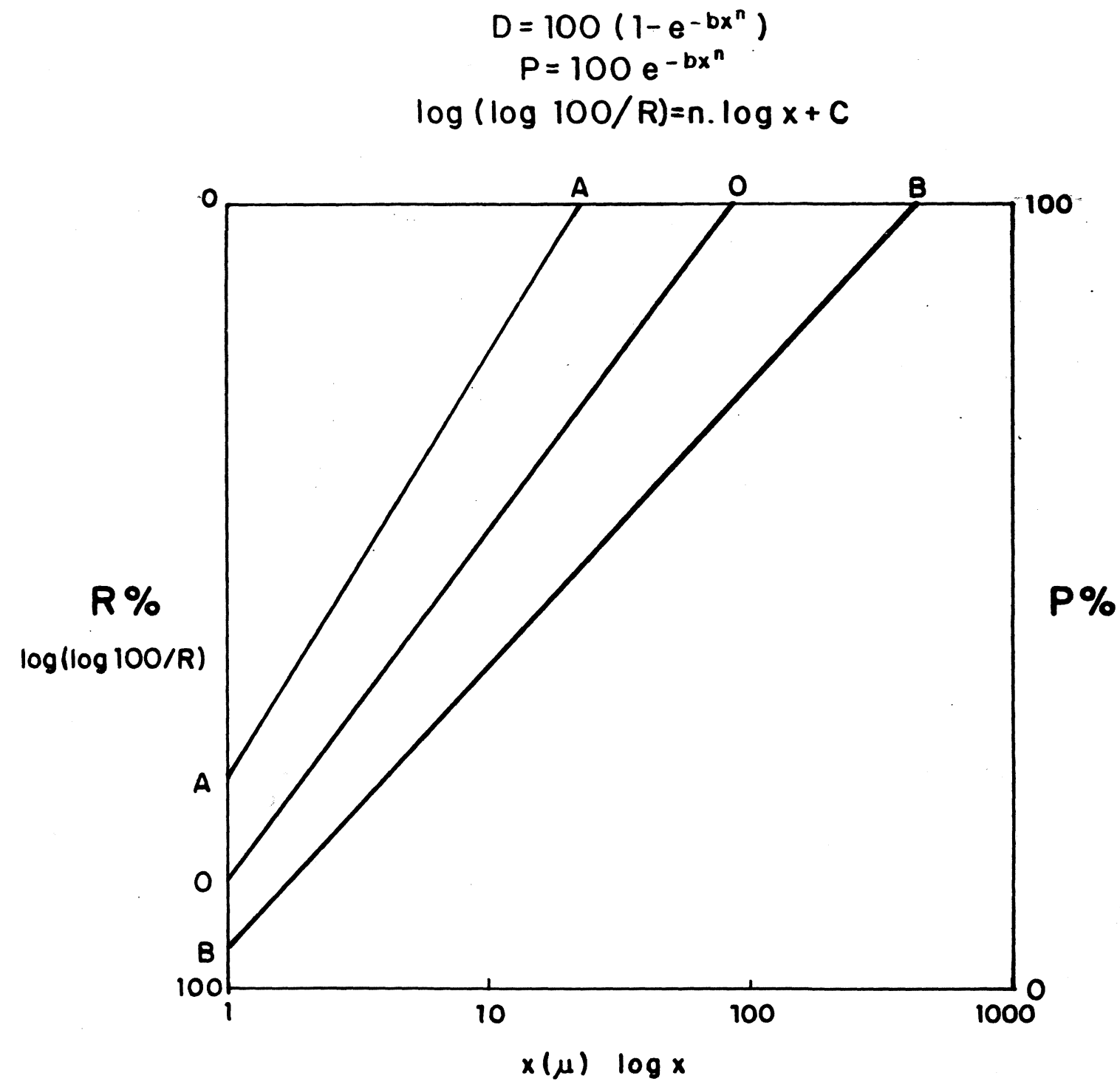

$A A$ más fino que 00 más fino que $B B$ 

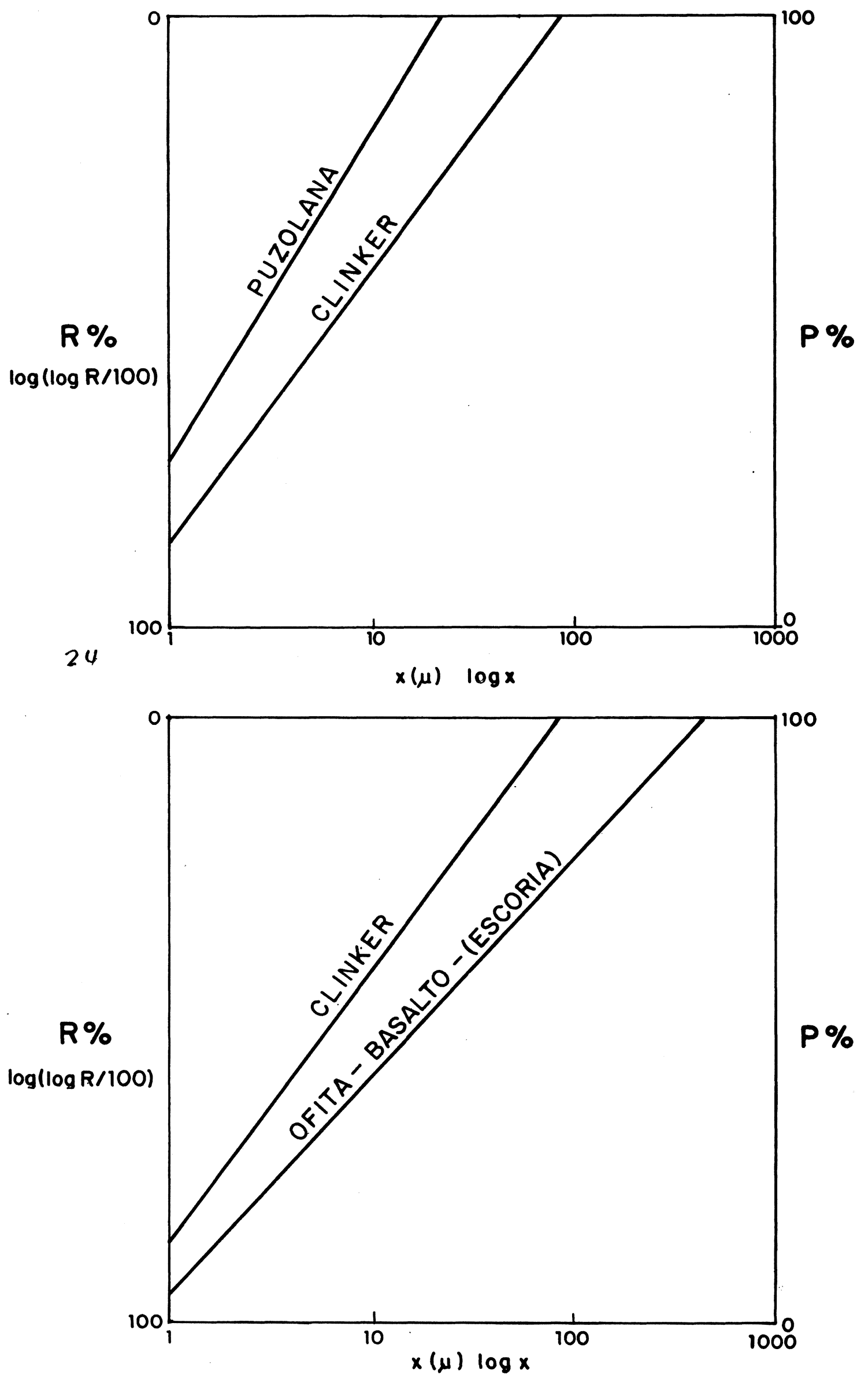
Gráfico de FRATINI

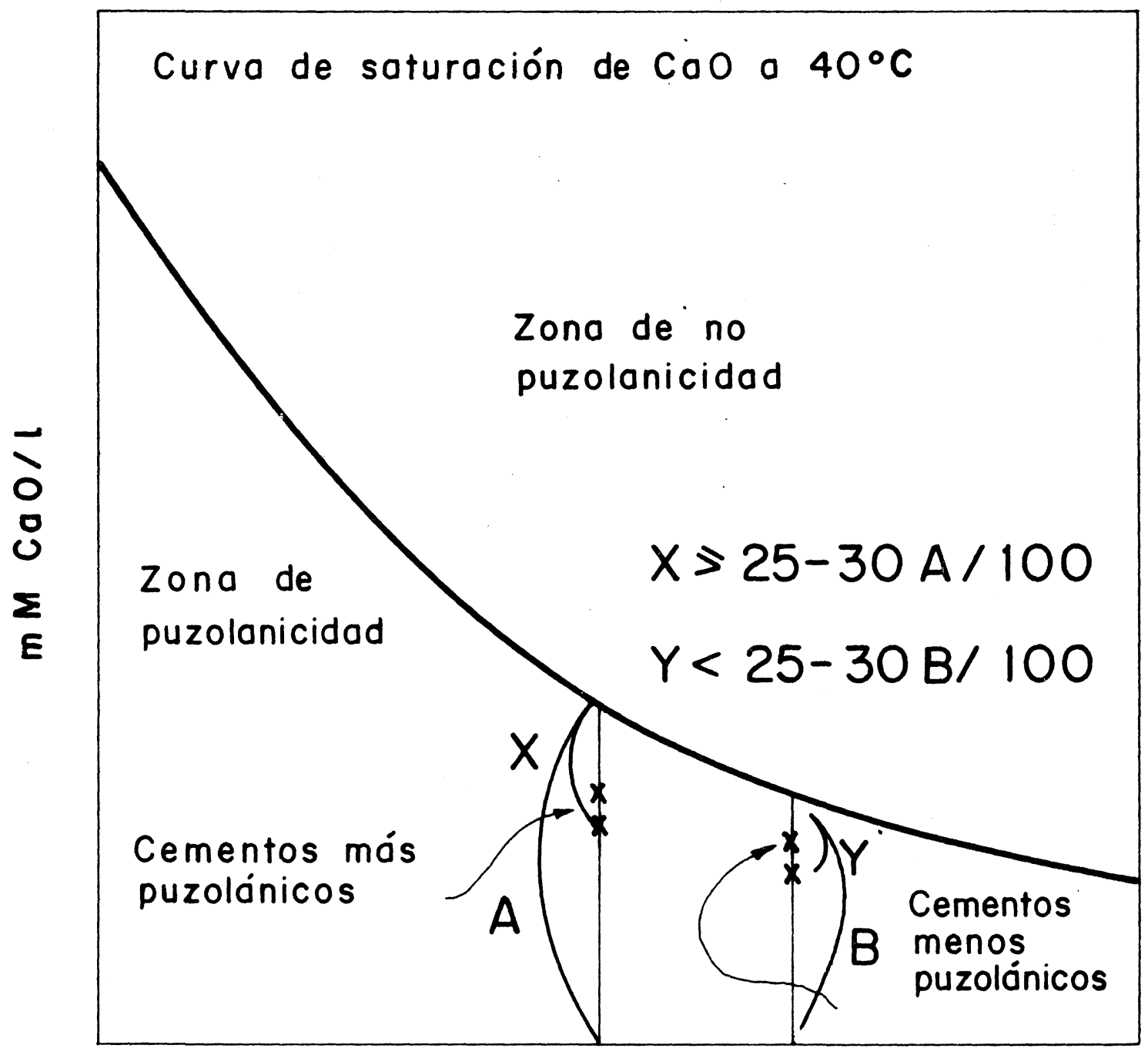

m M OH-/l 

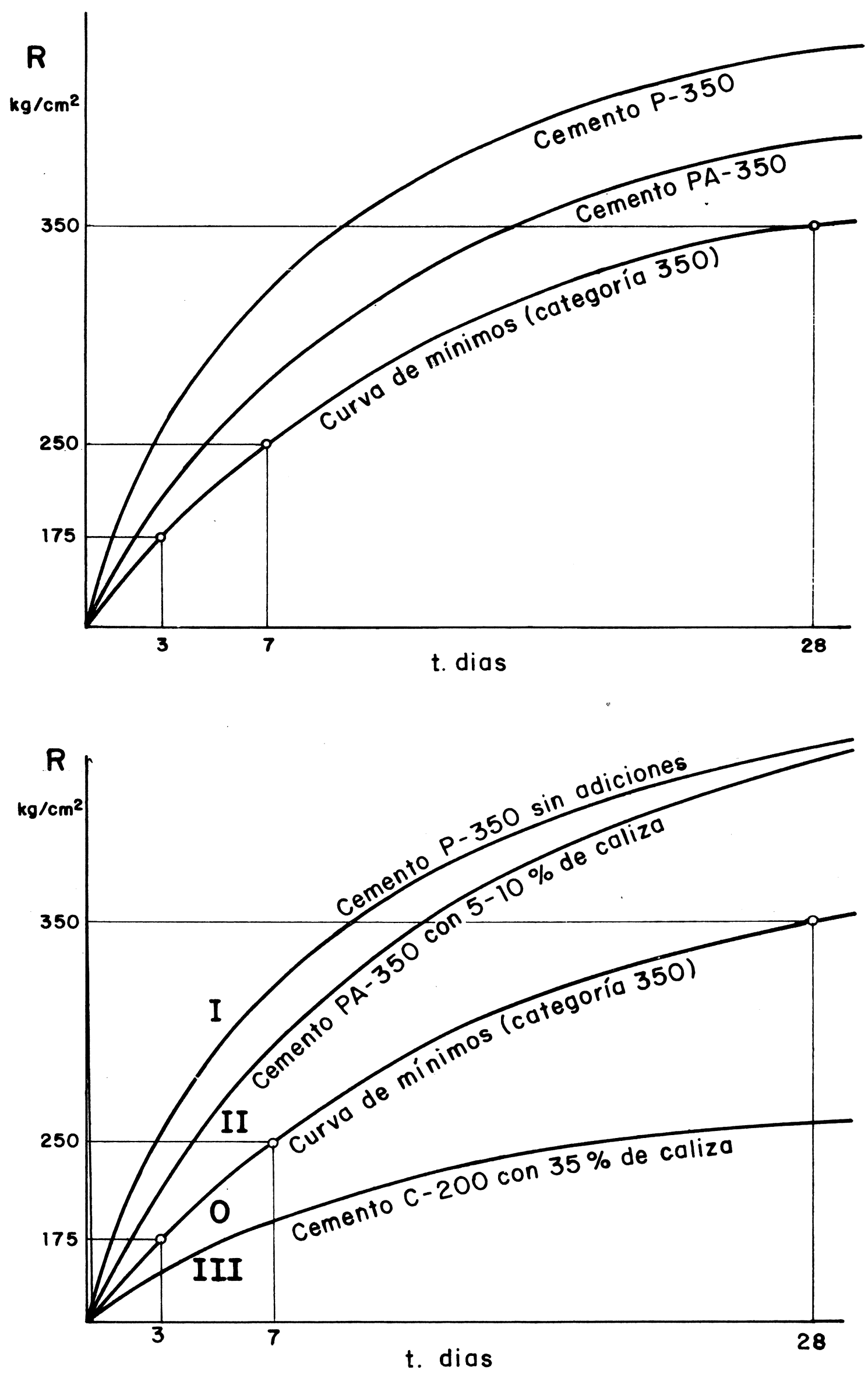

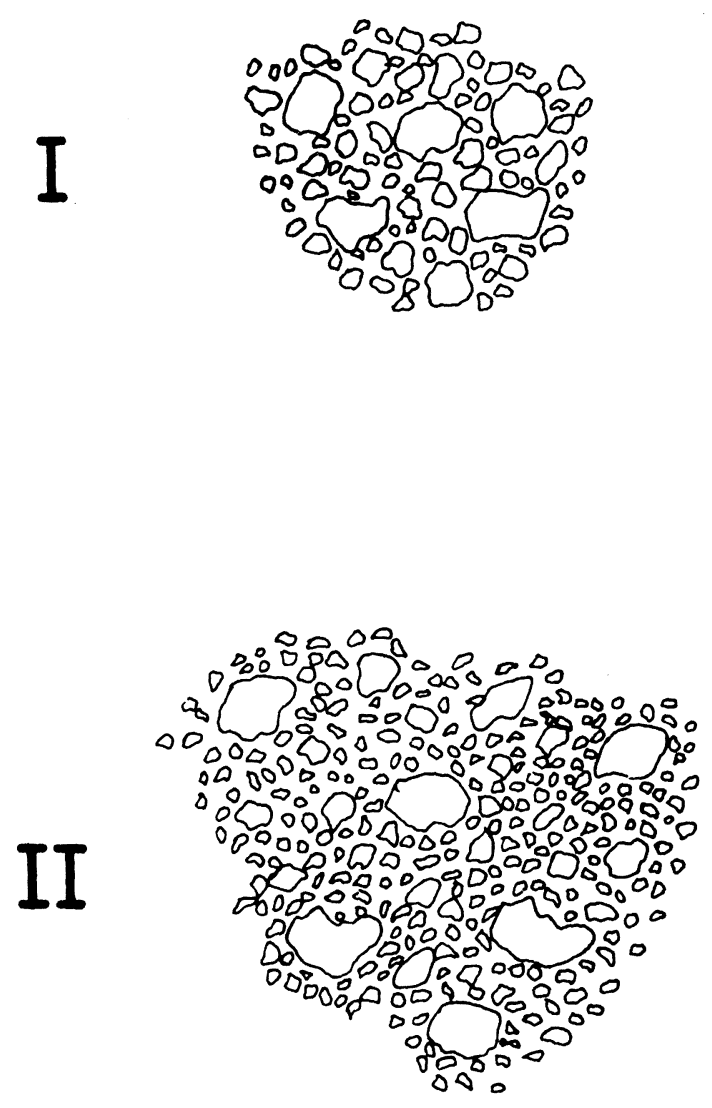

DISPERSION DE LAS PARTICULAS GRUESAS DEL CEMENTO

POR LAS MEDIANAS Y MAS FINAS DEL MISMO
DISPERSION MAYOR (MEJOR) DE LAS PARTICULAS GRUESAS Y MEDIANAS DEL CEMENTO POR LAS MEDIANAS $Y$ MAS FINAS DEL MISMO Y DE LA CALIZA
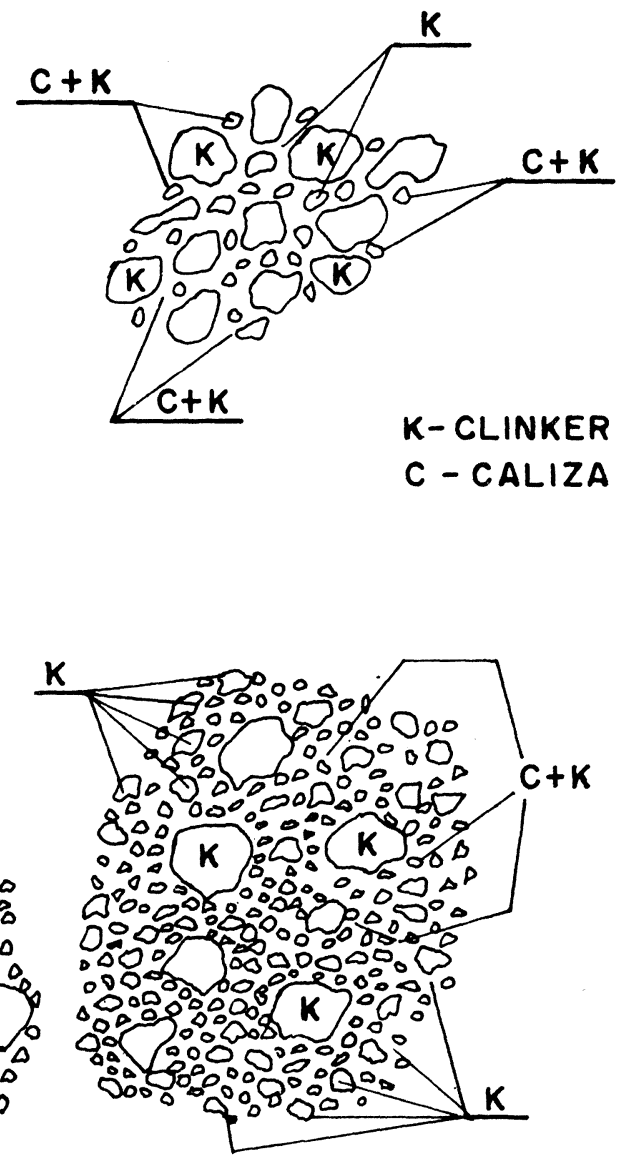
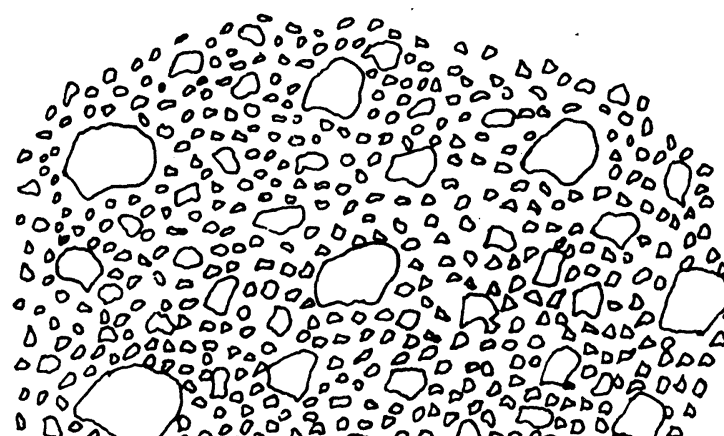

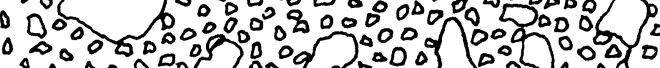

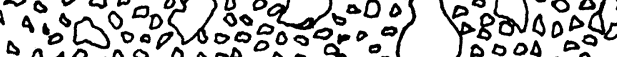

$\triangle 0000000000000$,

年 $\triangle 00 \%$ SIVA IDE LAS PARTICULAS GRUE$000000000_{0}^{\circ}$ SAS, MEDIANAS Y MAS FINAS DEL CEMENTO, POR LAS AUN MAS FINAS DE LA CALIZA. 

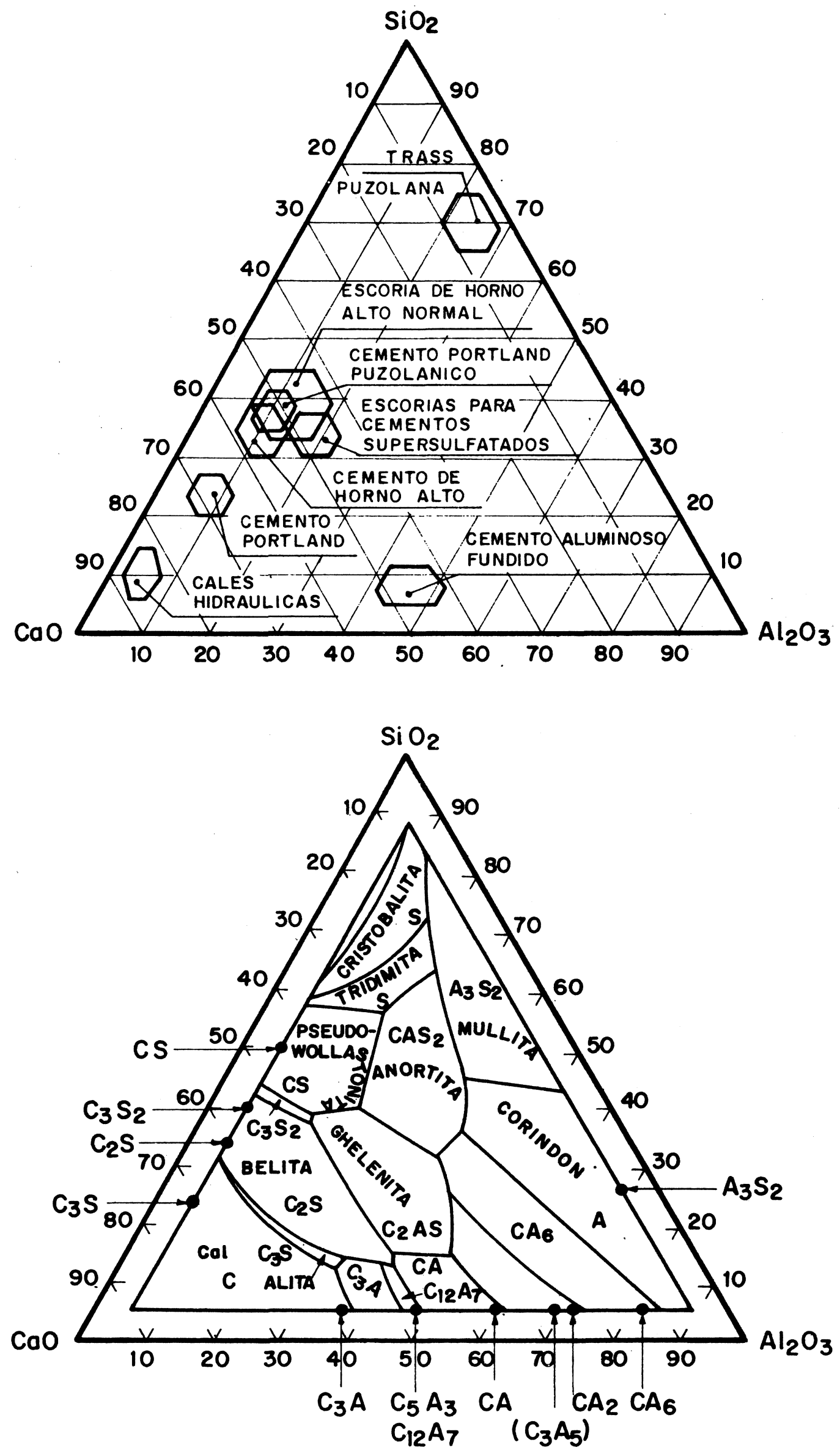


\section{COMPOSICION DE ESCORIAS SIDERURGICAS}

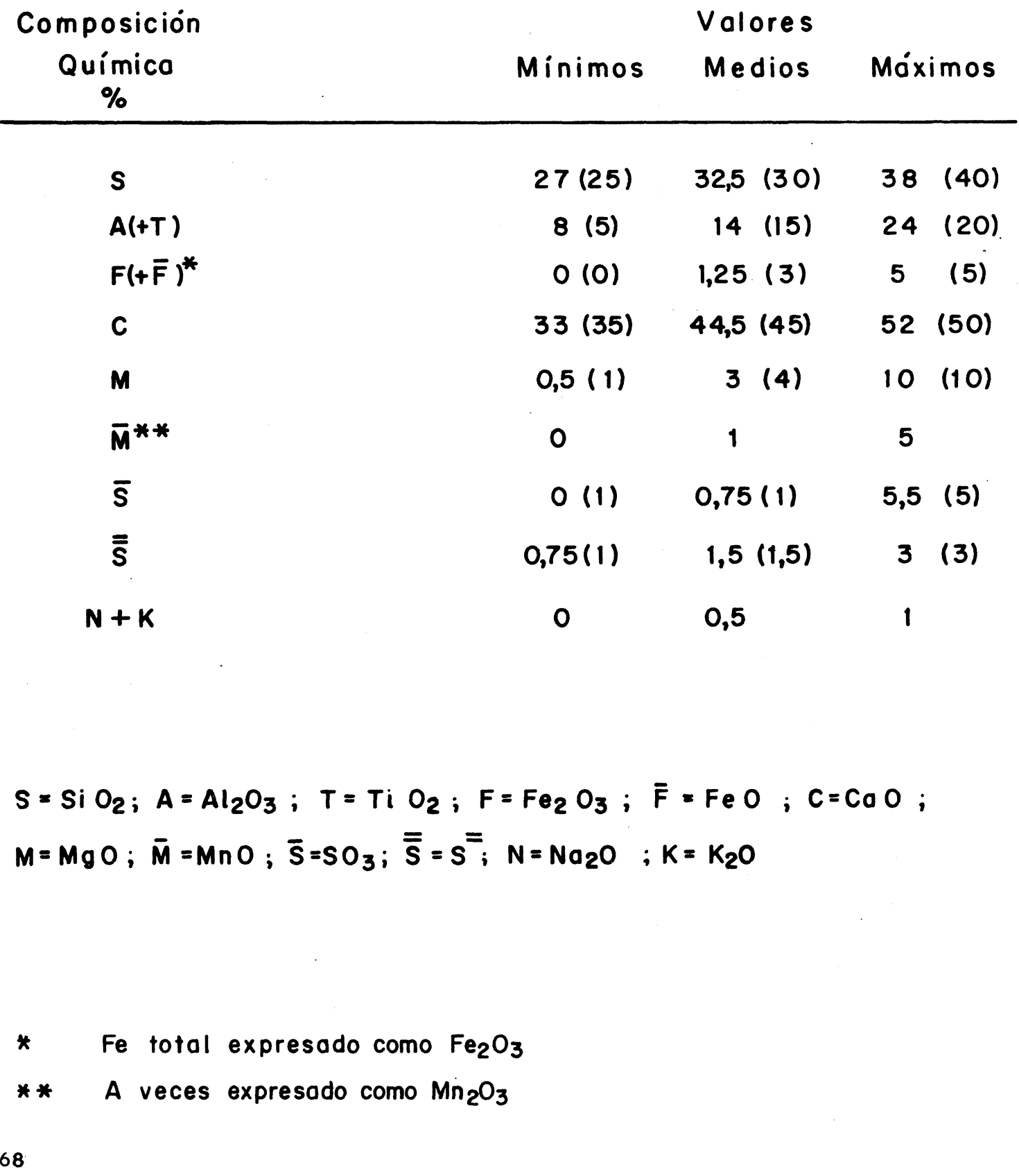




\section{INDICES DE ESCORIAS SIDERURGICAS PARA CEMENTOS DE HORNO ALTO}

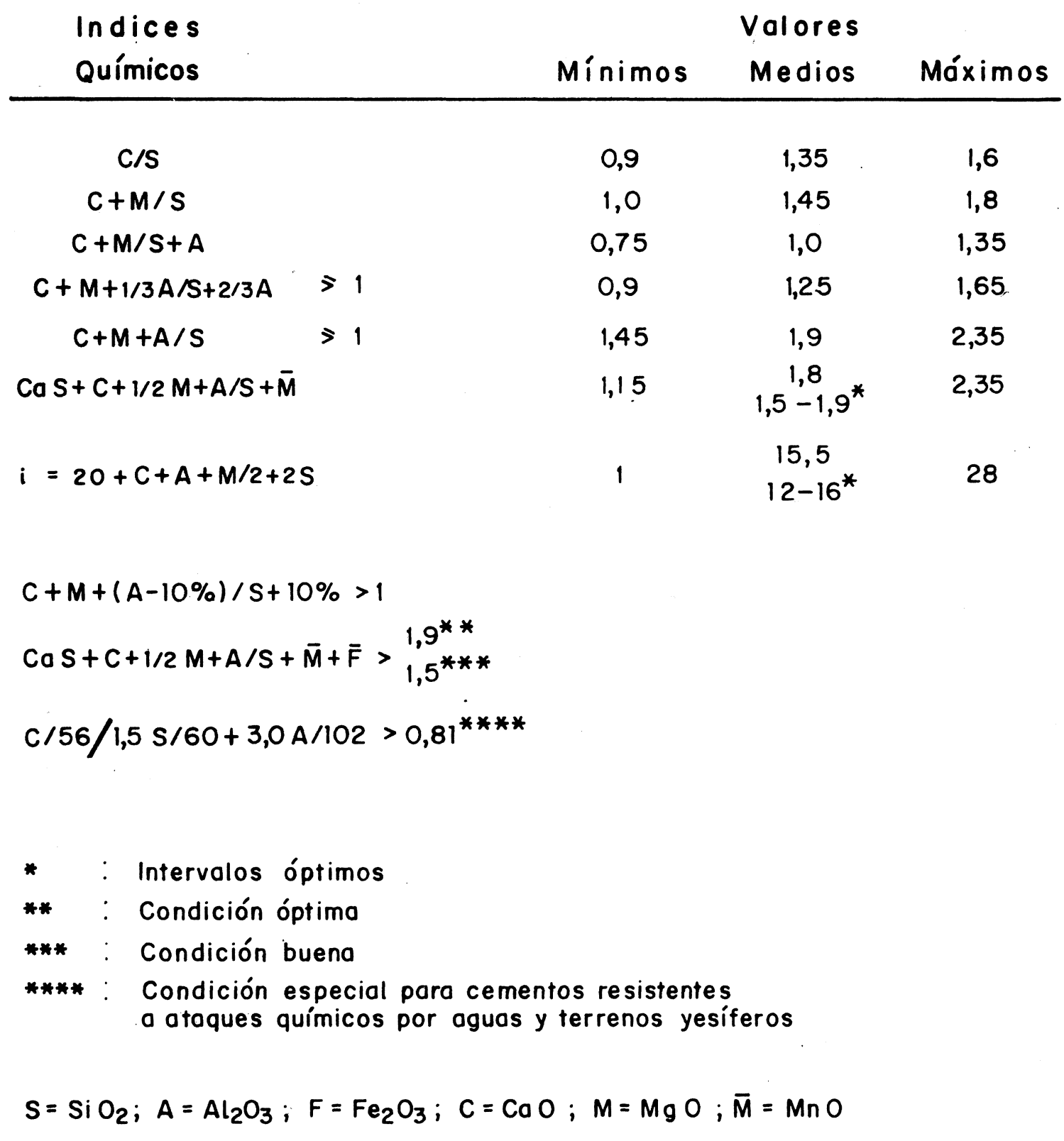

